\title{
HISTOLOGIA DOS SACOS HERNIÁRIOS DAS HÉRNIAS INGUINAIS INDIRETAS, DIRETAS, RECIDIVADAS E ENCARCERADAS EM ADULTOS E CRIANÇAS: IDENTIFICAÇÃO DE FIBRAS MUSCULARES LISAS
}

\author{
HISTOLOGY OF THE HERNIAL SACS OF DIRECT, INDIRECT, RELAPSED AND \\ INCARCERATED INGUINAL HERNIAS IN ADULTS AND CHILDREN: \\ IDENTIFICATION OF SMOOTH MUSCLES FIBERS
}

\author{
Cirênio de Almeida Barbosa, TCBC-MG ${ }^{1}$ \\ Vânia da Fonseca Amaral ${ }^{2}$ \\ Alcino Lázaro da Silva, TCBC-MG
}

\begin{abstract}
RESUMO: Objetivo: Pesquisar a presença de fibras de músculo liso (FML) nos sacos peritoneais das hérnias indiretas, diretas, recidivadas e encarceradas e estudar a influência do sexo, cor e idade dos pacientes, bem como a região do saco herniário, largura, comprimento e espessura da biópsia coletada. Método: Foram obtidos 252 sacos herniários no período de fevereiro de 1999 a dezembro de 2000 e encaminhados para o estudo histopatológico através da coloração por hematoxilina-eosina e tricrômico de Gomori. A idade variou entre um mês a 87 anos com média de 42,3 anos e desvio-padrão de 22,5 anos. Resultados: Foi utilizado o teste do Qui-quadrado e observada FML em 76,5\% dos pacientes com hérnia indireta, 55,9\% direta, 46,4\% encarcerada e 68,7\% recidivada. No estudo global foram encontradas FML em 67,9\% dos espécimes com maior incidência na porção proximal do saco herniário $(53,2 \%)$ e em pacientes melanodérmicos $(75 \%)$. As FML estiveram presentes em maior freqüência no lado direito $(67,7 \%)$ e no sexo feminino $(73,3 \%)$. Do total de 252 amostras de sacos herniários examinados, foi encontrada FML em 171 biópsias, e esse achado foi menos freqüente nas hérnias diretas e encarceradas quando comparadas com as indiretas e recidivadas. Conclusões: Como hipótese, a presença de FML na parede do saco herniário pode representar um reforço tecidual no sentido de dificultar o crescimento do saco peritoneal, comportando-se como fator de resistência elástica e dinâmica à expansão da hérnia. Por outro lado, pode também significar uma formação aberrante ou a persistência de uma estrutura que deveria regredir ou mesmo desaparecer durante o desenvolvimento normal.
\end{abstract}

Descritores: Hérnia inguinal; Saco herniário - fibras de músculo liso; Saco herniário - histologia.

\section{INTRODUÇÃO}

O tratamento do paciente com hérnia inguinal continua sendo um desafio para o cirurgião. É fundamental uma compreensão abrangente da anatomia e da fisiologia da região inguinal para se fazer uma abordagem segura nos pacientes portadores da afecção herniária. Ainda não possuímos a operação ideal para se obter a cura e, por conseguinte, o índice de recidivas oscila em torno de $10 \%$ nas operações para as afecções inguinais primárias convencionais ${ }^{1}$. Isso tem exigido do pesquisador o estudo da patogenia da doença herniária e a confirmação de importantes distúrbios no metabolismo do colágeno, onde haveria a explica-

1. Mestre e Doutor em Cirurgia, UFMG.

2. Professora Assistente de Patologia Geral do Instituto de Ciências Biológicas da UFMG.

3. Professor Titular de Cirurgia do Aparelho Digestivo da Faculdade de Medicina da UFMG.

Recebido em 06/11/2000

Aceito para publicação em 19/07/2001

Trabalho realizado no Curso de Pós-graduação do Departamento de Cirurgia da Faculdade de Medicina da UFMG. 
ção para as recidivas resultantes do enfraquecimento da fáscia transversal.

A protrusão herniária apresenta variações em sua patogenia e em suas manifestações patológicas. Dessa forma, sempre houve grande preocupação com o conteúdo do tumor herniário e com os reparos das estruturas músculo-aponeuróticas de reforço. Entretanto, alguns trabalhos valorizam o conhecimento anatomopatológico e histológico da estrutura sacular ${ }^{2-5}$. Os resultados, da morfologia macro e microscópica do saco herniário, até então conhecidos, favorecem o seu uso na correção cirúrgica das hérnias da parede abdominal e também na identificação de condições patológicas ocultas ${ }^{6}$. Somada a isso a constituição do peritônio sacular apresenta exuberância de FML na sua parede, junto a tecido conjuntivo fibroso, fibras elásticas e reticulares e até mesmo a sua confirmada modificação e transformação tecidual em aponeurotização, apontando para o seu aproveitamento nas hernioplastias da parede abdominal ${ }^{7}$. Nessa linha de pesquisa, iniciada por Lázaro da Silva ${ }^{8}$, encontramos na literatura trabalhos que visam à valorização do divertículo herniário e, por extensão, à procura de maiores esclarecimentos para a etiopatogenia da doença inguinal ${ }^{1-4,9}$. De fato, alguns pesquisadores, preocupados com os fatores etiopatogênicos, estudaram os defeitos congênitos ou mesmo as influências que interferem na síntese ou na renovação do colágeno e o conseqüente aparecimento desta patologia.

O saco peritoneal constitui-se de um tecido biológico autólogo, com características teciduais reparativas, boa fibroplasia local e vem sendo estudado desde $1971 \mathrm{com}$ início na hérnia incisional ${ }^{10}$. Desde então, com este resultado positivo, Lázaro da Silva iniciou também o emprego do saco herniário inguinal no reforço do triângulo inguinal nas hérnias desta região ${ }^{7}$. À microscopia de luz, observou-se que a estrutura sacular peritoneal é constituída por mesotélio, tecidos conjuntivos de reparação, colágeno e também por FML, elásticas e reticulares. Revendo os trabalhos publicados por Lázaro da Silva ${ }^{11,12}$, Orsi ${ }^{13}$, Sou$\mathrm{za}^{9}$ e Barbosa ${ }^{4}$, verificamos que o melhor conhecimento de sua estrutura justifica a utilização do próprio saco peritoneal em pacientes portadores de hérnias inguinais indiretas e diretas, para reforçar o assoalho inguinal sem tensão. A origem das FML parece depender da capacidade de diferenciação dos pericitos e do potencial estimulador dessas células ${ }^{14-15}$. Essas células normalmente são encontradas no endotélio dos capilares e das vênulas e, quando estimuladas, diferenciam-se em fibroblastos, FML e miofibroblastos.

\section{MÉTODO}

O estudo constou de 252 sacos herniários retirados de 233 pacientes clinicamente selecionados para o tratamento operatório de hérnias inguinais e que foram divididos em quatro grupos.

- Grupo 1 - portadores de hérnia inguinal indireta

- Grupo 2 - portadores de hérnia inguinal direta

- Grupo 3 - portadores de hérnia inguinal, indireta ou direta, recidivada
- Grupo 4 - portadores de hérnia inguinal, indireta ou direta, encarcerada com ou sem estrangulamento.

A idade dos pacientes variou entre um mês de vida e 87 anos, com média de 42,3 anos e desvio-padrão de 22,5 anos. Dos pacientes operados, $94 \%$ corresponderam ao sexo masculino e $6 \%$ ao feminino. Verificou-se que 54\% eram feodérmicos, $42,8 \%$ leucodérmicos e uma ocorrência de 3,2\% de melanodérmicos. Quanto à localização, os 233 pacientes foram assim distribuídos: $62,7 \%$ do lado direito e $37,3 \%$ do esquerdo.

\section{HérNIA INDIRETA}

A via de acesso padronizada nos adultos foi pela região inguinal, paralela ao ligamento inguinal, a $2 \mathrm{~cm}$ medialmente à arcada de Poupart. Nas crianças e nas mulheres deu-se preferência à incisão transversa, na prega natural da pele, localizada a $3 \mathrm{~cm}$ distante do lado externo da arcada de Poupart.

Após a realização da ligadura e secção do saco herniário, este era medido e, de imediato, aberto no seu maior eixo para um estudo anatomopatológico minucioso. Os sacos herniários eram identificados com um fio de seda 2.0 nas duas extremidades: um de $10 \mathrm{~cm}$ marcava o fundo e outro de $5 \mathrm{~cm}$ identificava o colo. A amostra era enrolada em espiral com a ajuda de duas pinças hemostáticas retas de $10 \mathrm{~cm}$ e depois anodada com fios de seda 3.0 para preservar a forma anatômica da espiral. A face externa da forma "rocambole" correspondia à face peritoneal dos sacos herniários.

O movimento de espiralação era iniciado pela movimentação circular horária de uma das pinças fixadas a uma das extremidades, enquanto a outra pinça era mantida fixa. A amostra era mergulhada em solução de formol a $10 \%$ por um período mínimo de 12 horas.

Em espécimes herniários pequenos e que não podiam ser incluídos no procedimento anterior, eram identificados o colo e o fundo. A seguir, os mesmos eram abertos no seu maior eixo, dispostos e estendidos em folha de papel cartolina, estando presos com alfinetes para permanecerem esticados na solução de formol a $10 \%$.

\section{Hérnia Direta}

O saco herniário exteriorizado pela fosseta média era apreendido pela sua cúpula com uma pinça hemostática reta de $10 \mathrm{~cm}$. A seguir um fragmento, de no mínimo $0,5 \mathrm{~cm}$, era retirado em forma de calota e marcado nas suas extremidades medial e lateral. Imediatamente esse fragmento era estendido sobre um papel cartolina com o auxílio de pequenos alfinetes e, depois, mergulhado em um vidro de boca larga contendo formol a $10 \%$, onde permanecia por no mínimo 12 horas.

A técnica de biopsia para as hérnias recidivadas e encarceradas obedeceu aos mesmos princípios das hérnias indireta ou direta.

As amostras eram imersas em parafina totalizando três blocos para cada espécime. Foram feitas três lâminas 
de inclusão de parafina da base do saco herniário, três da parte intermediária e finalmente mais três do bloco de parafina correspondente ao fundo. Convencionou-se que o colo seria marcado com a letra $\mathrm{P}$ (proximal), a parte intermediária com a letra $\mathrm{M}$ (medial) e o fundo com a letra D (distal).

Numa primeira etapa as lâminas eram coradas pela HE para evidenciação panorâmica dos elementos constituintes da amostra. Dessa forma os componentes conjuntivos e musculares coravam-se em tom rosa-claro nítido ou vermelho. Em seguida, e muito especificamente para a identificação e o estudo das fibras musculares, as lâminas recebiam a coloração pelo tricrômico de Gomori em que o tecido conjuntivo presente nos fragmentos se corava em verde e as fibras musculares em vermelho (Figuras 1 e 2).

Nos cortes histológicos corados em HE e pelo tricrômico de Gomori foi avaliada subjetivamente a quantidade de fibras de colágeno e de FML, em cada uma das lâminas, excluindo-se as FML da parede vascular.

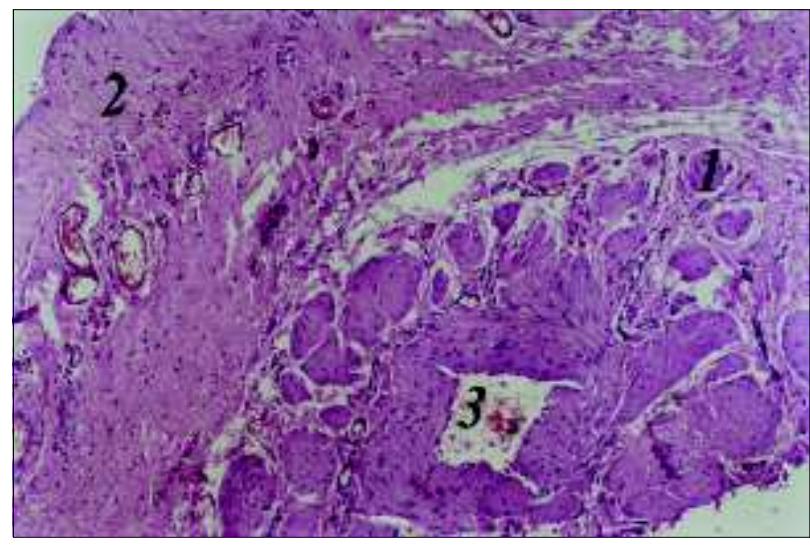

Figura 1 - Fotomicrografia de parede de saco herniário inguinal - Observar - FML (1), tecido fibroso (2) e vasos sangüíneos (3) $-H E-25 x$.

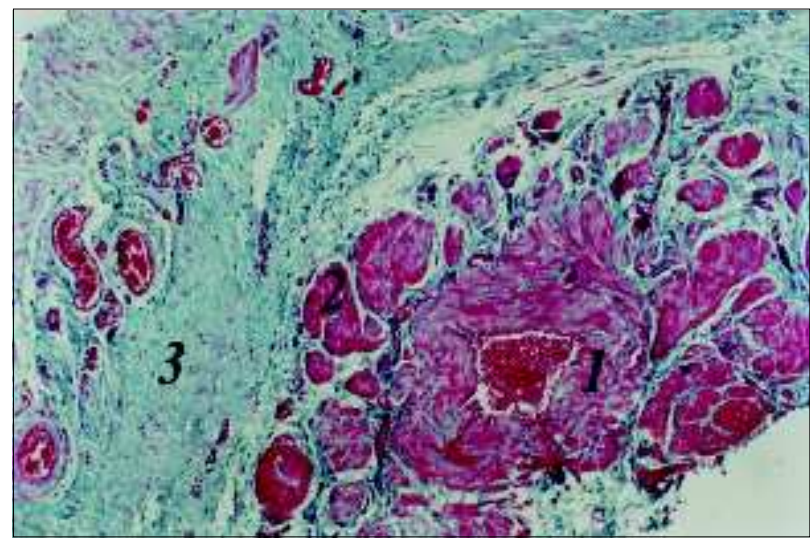

Figura 2 - Fotomicrografia de saco herniário de hérnia inguinal Observar - FML (1) em parede de vaso, FML em feixes periféricos (2) e tecido fibroso (3) - Tricrômico de Gomori - 25x.
Nessas avaliações foi utilizada a objetiva de $4 \mathrm{x}$ e adotando-se os seguintes critérios:

- pequena quantidade: o colágeno representava até $50 \%$ da espessura da parede do saco herniário, considerando-se os sacos de paredes delgadas;

- média quantidade: o colágeno representava $51 \%$ a $75 \%$ da espessura da amostra, considerando-se suas paredes mais espessas;

- grande quantidade: o colágeno representava mais de 75\% da espessura do espécime;

- pequena quantidade: quando os feixes de músculo liso representavam até $10 \%$ dos componentes do saco herniário;

- média quantidade: quando as FML representavam de $11 \%$ a $50 \%$ dos componentes dos espécimes;

- grande quantidade: quando o conteúdo de FML representava mais de $50 \%$ da sua constituição.

\section{RESULTADOS}

No estudo foram observadas $59,1 \%$ dos pacientes com hérnias inguinais indiretas, $23,4 \%$ diretas, $11,1 \%$ encarceradas e $6,4 \%$ recidivadas. Observou-se a presença de FML em 67,9\% dos sacos herniários e em 32,1\% das mesmas essas fibras não foram encontradas nas amostras. Estudando a histopatologia dos sacos herniários nas suas três porções distintas, foram observados $53,2 \%$ de FML nas porções proximal, em $44,4 \%$ intermediária e em $38,9 \%$ distal. Verificou-se, independentemente do tipo de hérnia, a presença de FML em quantidades variáveis nos espécimes. Houve uma predominância, nas biopsias, de pequena quantidade de FML, quando foi analisado globalmente. A presença de grande quantidade de FML foi observada em menos de $13 \%$ das amostras.

A avaliação da existência de FML, quando comparada com o tipo de hérnia, demonstrou uma maior incidência dessas fibras nos espécimes de sacos herniários de hérnias indiretas e recidivadas (Tabela 1). Esse resultado apresentou uma significância estatística com p=0,002.

De modo geral, observou-se a presença de FML em $73,3 \%$ das amostras dos sacos das hérnias inguinais em mulheres e em $67,5 \%$ nas dos homens, e esta diferença não foi significante quando se aplicou o teste exato de Fisher $(\mathrm{p}=0,780)$. Observou-se nas amostras de saco herniário dos pacientes feodérmicos $67,7 \%$ de FML, nos leucodérmicos $67,6 \%$ e nos melanodérmicos $75 \%$ de ocorrência de FML. Constatou-se, também, na comparação dos grupos, que não houve a influência da cor. O teste do Qui-quadrado mostrou $\mathrm{p}=0,908$. Este resultado foi encontrado tanto na análise global quanto na avaliação específica para cada tipo de hérnia.

Verificou-se também que as amostras contendo FML ocorreram em $67,7 \%$ do lado direito, e no lado esquerdo este percentual foi igual a $68,1 \%$ e com $p=0,952$ quando aplicado o teste de Qui-quadrado. No que diz respeito à idade, os resultados apresentados mostraram que os pacientes que tinham FML não diferem significativamente dos demais quando utilizado o teste de Kruskal-Wallis 
Tabela 1

Distribuição das biopsias de acordo com a pesquisa de FML e o tipo de hérnia inguinal operada

\begin{tabular}{|c|c|c|c|c|c|c|c|}
\hline \multirow{3}{*}{ Tipo de hérnia } & \multicolumn{4}{|c|}{ Músculo liso } & \multirow{3}{*}{$\begin{array}{c}\text { Total } \\
\text { de sacos }\end{array}$} & \multirow[b]{3}{*}{$p$} & \multirow[b]{3}{*}{ Conclusão } \\
\hline & \multicolumn{2}{|c|}{ Presente } & \multicolumn{2}{|c|}{ Ausente } & & & \\
\hline & $n$ & $\%$ & $n$ & $\%$ & & & \\
\hline Direta & 33 & 55,9 & 26 & 44,1 & 59 & & \\
\hline Encarcerada & 13 & 46,4 & 15 & 53,6 & 28 & & \\
\hline Indireta & 114 & 76,5 & 35 & 23,5 & 149 & 0,002 & $(\mathrm{D}=\mathrm{E})<(\mathrm{I}=\mathrm{R})$ \\
\hline Recidivada & 11 & 68,7 & 5 & 31,3 & 16 & & \\
\hline Total & 171 & 67,9 & 81 & 32,1 & 252 & & \\
\hline
\end{tabular}

Nota: A probabilidade de significância refere-se ao teste do Qui-quadrado.

$D=$ direta $; E=$ encarcerada $;=$ indireta e $R=$ recidivada.

( $\mathrm{p}=0,261)$. Quanto ao comprimento da amostra, não foram assinaladas diferenças significantes entre o tipo de hérnia cujas amostras apresentaram FML e aquelas que não apresentaram. Quanto à largura da biopsia do saco herniário, também não foram verificadas diferenças significantes entre o tipo de hérnia com e sem FML. Em relação à espessura do espécime, quando correlacionou com os tipos de hérnias, foi observada uma tendência à significância estatística $(\mathrm{p}=0,065)$ e com especial interesse no grupo de hérnia direta $(\mathrm{p}=0,071)$.

\section{DISCUSSÃO}

Na última década, o uso do saco herniário no reforço do assoalho da região inguinal foi justificado por ser constituído de peritônio, fáscia transversal, tecido colágeno, fibras elásticas, reticulares e de músculo liso. Lázaro da Silva ${ }^{16}$, Lázaro da Silva et al. ${ }^{12}$, Barbosa ${ }^{3}$ e Barbosa et $a l .{ }^{1}$ em publicações recentes apontaram para os novos achados na sua constituição histológica e demonstraram a presença de fibras reticulares, elásticas, aponeurotização do colágeno e FML. Nesses casos eram representados ora por fibras isoladas, ora por feixes grosseiros, muitas vezes em associação com vasos sangüíneos espessos, o que sugeriu sua origem a partir da camada média da parede vascular de acordo com o trabalho original de Lázaro da Silva et $a l .{ }^{12}$. Em certas regiões essas fibras musculares eram bem desenvolvidas e tendiam a se dispor formando camadas de dimensões variadas. A impressão era de que a proliferação de musculatura lisa na parede do saco peritoneal mantinha relação com vasos neoformados, embora isso não foi observado nas biopsias-controle do peritônio da cavidade abdominal realizadas por Barbosa et al. ${ }^{4}$. Fato interessante em alguns espécimes era a proliferação desordenada de FML na parede dos vasos e a formação de camadas mais ou menos definidas, o que está em acordo com os achados de Tanyel et al. ${ }^{17}$. A presença de fibras de FML, elásticas e reticulares, já demonstrada por Lázaro da Silva et al..$^{12}$ e Barbosa et $a l .{ }^{4}$, e o predomínio de fibras colágenas densas e ordenadas permitem que o saco herniário seja resistente e passível de ser usado no reforço do assoalho inguinal conforme demonstrado por Shafey \& Azzam $^{18}$, Popov \& Sorokina ${ }^{19}$, Pucci $^{20}$, Lázaro da Silva $^{7}$ e Souza ${ }^{9}$.

O achado interessante do estudo histológico do saco herniário inguinal foi a existência de FML na sua parede, de permeio a tecido conjuntivo e relatado por Lázaro da Silva et al. ${ }^{12}$, Souza ${ }^{9}$ e Barbosa ${ }^{1}$ e em trabalhos recentemente publicados por Andriani ${ }^{2}$ e Barbosa et al. ${ }^{4}$. Foi observada também uma grande proliferação vascular, às vezes angiomatóide ou mesmo hamartomatosa. Essa neoformação vascular presente nos processos reparativos é dependente de citocinas, bem como a proliferação e a diferenciação celular. Seria possível, a partir deste conhecimento, acreditarmos na possibilidade do aparecimento ou aumento da população de FML nos sacos herniários, como um processo reacional, ou seja, de resposta ao trauma mecânico ou a outros fatores envolvidos na patogênese da hérnia inguinal. Como hipótese, pode-se argumentar que as FML presentes na parede do peritônio sacular representariam um reforço tecidual no sentido de dificultar o crescimento da hérnia, comportando-se como fator de resistência elástica e dinâmica à expansão da doença herniária e, portanto, representar um elemento importante na etiopatogênese da afecção herniária. Por outro lado, a presença de feixes de FML também pode significar uma formação aberrante ${ }^{21}$ ou a persistência de uma estrutura que deveria regredir ou mesmo desaparecer durante o desenvolvimento normal. Pode-se aventar, finalmente, a sua origem a partir da camada média da parede de vasos do saco herniário. As FML existentes na região do dartos ou labioescrotal, por extensão do processo vaginal e pela certificação de sua frequiência na região cranial do divertículo herniário, entretanto, podem representar um fator de impedimento na obliteração do conduto peritônio-vaginal e conseqüente formação da hérnia inguinal e da hidroce- 
le. Os estudos histológicos demonstraram que os espécimes eram constituídos por uma membrana conectiva vascular que apresentava diversas imagens histológicas, provavelmente etapas de uma mesma evolução. Uma delas correspondia a um tecido conjuntivo frouxo sem diferenciação laminar, muito vascularizado e com abundantes fibroblastos em atividade proliferativa, especialmente em direção a uma de suas faces. Outra correspondia a uma membrana com diferenciação laminar concêntrica, cada uma constituída por fibras colágenas orientadas em sentidos variados. Finalmente, foi observada a existência de FML de permeio ao tecido conjuntivo e a distribuição destes fascículos sugeriu sua origem a partir da camada média dos vasos existentes na estrutura sacular ou ainda a partir de FML preexistentes ${ }^{12}$.

É notório que o cirurgião sempre se preocupou com a anatomia da região, com o orifício e o conteúdo, desconhecendo, no entanto, os aspectos histopatológicos de relevância do saco herniário.

Os resultados dos estudos de Lázaro da Silva et al. ${ }^{11}$, Barbosa $^{3}$ e Souza ${ }^{9}$ mostraram que o conhecimento da morfologia macro e microscópica da estrutura sacular peritoneal pode trazer implicações importantes porque permite o uso do mesmo na correção cirúrgica das hérnias da parede abdominal e também na identificação de condições patológicas encobertas como mostraram Sanella ${ }^{6}$, Chen ${ }^{22}$ e Barbosa $^{3}$.
O saco herniário pode ser sede de processos patológicos diversos que atingem o peritônio parietal. É o caso da endometriose, de inflamações específicas e de processos hiperplásicos ou mesmo neoplásico. O seu comprometimento por mesoteliomas ou metástases de diversas neoplasias malignas não é infreqüente; notadamente na parede sacular e isso já foi relatado nos trabalhos de Chen ${ }^{22}$. O encarceramento ou o encontro de um conteúdo irredutível no primeiro exame, principalmente em indivíduos idosos, faz pensar na possibilidade de doença maligna associada. Outros achados não menos importantes são relatados, como ovos de Shistosoma mansoni e granulomas na parede do saco herniário ${ }^{12}$, bem como o encontro de tecido de supra-renal, já demonstrado por Barbosa \& Lázaro da Silva ${ }^{3}$ e Barbosa et $a l .{ }^{4}$.

Conclui-se que o conhecimento da morfologia macro e microscópica da estrutura sacular peritoneal pode trazer implicações importantes porque permite o uso do mesmo na correção cirúrgica das hérnias inguinais pela sua riqueza constitucional de FML e também de colágeno. Por outro lado, o seu estudo histológico permite o diagnóstico de processos patológicos diversos que acometem o peritônio parietal. Como hipótese, a presença de FML na parede do saco herniário pode representar um reforço tecidual no sentido de dificultar o crescimento do saco.

\begin{abstract}
Background: To determine the presence of smooth muscle fibers $(S M F)$ in the peritoneal sacs of indirect, direct, recurrent and strangulated hernias and to evaluate the influence of sex, color and patients'age well as location, width, length and thickness of the hernia sac collected biopsy. Method: 252 hernia sacs - obtained between February 1999 and December 2000 - were sent to histopathological examination using hematoxylin and eosin

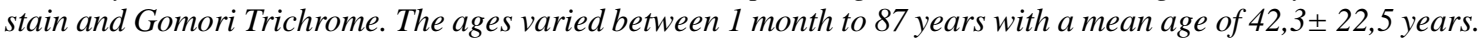
Results: SMF were observed in 76,5\% of the patients with indirect hernia, 55,9\% with direct hernia, 46,4\% with strangulated hernia and 68,7\% with recurrent hernia. Overall, SMF were found in 67,9\% of the specimens, with larger incidence in the proximal portion of the hernia sac (53,2\%), and in melanodermic patients (75\%). SMF were present, in larger frequency, on the right side $(67,7 \%)$ and in the feminine sex $(73,3 \%)$. Of the total of 252 samples of examined hernia sacs, SMF were found in 171 biopsies, wich wass less frequent in direct and strangulated hernias when compared with to indirect and recurrent hernias. Conclusions: The presence of SMF in the hernia sac wall could represent tissue reinforcement by hindering peritoneal sac growth, behaving as factor of elastic and dynamic resistance to the hernia expansion. On the other hand, it could also mean an aberrant formation or persistence of a structure that could be subject to regression or even disappear during normal development.
\end{abstract}

Key Words: Inguinal hernias; Hernia sac — smooth muscle fibers (SMF); Hernia sac — histology.

\title{
REFERÊNCIAS
}

1. Barbosa CA, Lázaro da Silva A. "Saco herniário”. In: Lázaro da Silva A - Hérnias da parede abdominal 1. Rio de Janeiro. Colégio Brasileiro de Cirurgiões, 1997, pp.131-139.

2. Andriani AC. Avaliação histológica do saco herniário de hérnias inguinais. Dissertação (Mestrado em Cirurgia Abdominal). Florianópolis. Universidade Federal de Santa Catarina, 2000, 112p.
3. Barbosa CA. Histopatologia do saco herniário da hérnia inguinal indireta e do peritônio parietal em adultos e crianças: estudo qualitativo da sua musculatura lisa. Dissertação (Mestrado em Cirurgia Abdominal). Belo Horizonte. Universidade Federal de Minas Gerais, 1997, 144p. 
4. Barbosa CA, Amaral VF, Lázaro da Silva A. Histopatologia do saco herniário da hérnia inguinal indireta e do peritônio parietal em adultos e crianças: estudo qualitativo da sua musculatura lisa. Rev. Col. Bras. Cir, 2000, 27: 183-188.

5. Faria LP. Estudo histológico e imuno-histoquímico do saco herniário de hérnias inguinais indiretas no homem. Dissertação (Doutorado em Cirurgia Abdominal). Belo Horizonte. Universidade Federal de Minas Gerais, 2000, 67p.

6. Sanella NA. Inguinal hernia and colon carcinoma. Presentatioon of a series and analysis. Surgery, 1973, 73: 434-437.

7. Lázaro da Silva A. Correção cirúrgica das hérnias inguinais usando-se o saco herniário como reforço. In: Lázaro da Silva A. Hérnias. São Paulo. Liv. Roca Ltda; 1992, pp.738-739.

8. Lázaro da Silva A. O uso do saco herniário no reforço da hernioplastia inguinal. Rev. Col. Bras. Cir. 1995, 3:153-154.

9. Souza PL, Lázaro da Silva A. Emprego do saco herniário no reforço parietal nas hérnias inguinais indiretas no adulto. Rev. Col. Bras. Cir, 1977, 25:193-199.

10. Lázaro da Silva A. "Emprego do saco herniário na correção cirúrgica de hérnia incisional na criança." In: Lázaro da Silva A. Hérnias. São Paulo. Liv. Roca Ltda; 1992, pp. 629-630.

11. Lázaro da Silva A. Patologia do saco herniário. In: Lázaro da Silva A. Hérnias. São Paulo. Liv. Roca Ltda., 1992, pp.1037-1040.

12. Lázaro da Silva A, Brasileiro Filho G, Ferreira AP. Estudo morfológico do saco herniário inguinal. Rev. Hosp. Clin. Fac. Med. S.P, 1992, 47: 65-68.

13. Orsi FL, Marinho EB, Lougon LA et al. Reforço da parede posterior nas hérnias inguinais com o próprio saco herniário. Rev. Col. Bras. Cir. 1995, 22: 151, Suplemento 2 .
14. Ham AW. Tecido conjuntivo. In: Ham AW. Histologia 7a ed. Rio de Janeiro. Guanabara Koogan, 1977, pp.170-181.

15. Junqueira LC, Carneiro J. Tecidos conjuntivos. In: Junqueira LC, Carneiro J. Histologia Básica 7a ed. Rio de Janeiro. Guanabara Koogan, 1990, pp.65-87.

16. Lázaro da Silva A. Tratamento (ligadura) do saco herniário. In: Lázaro da Silva A. Hérnias. São Paulo. Liv. Roca Ltda., 1992; pp. 736-737.

17. Tanyel FC, Dagdeviren A, Müftüoglu S et al. Inguinal hernia revisited through comparative evaluation os peritoneum, processus vaginalis, and sacs obtained from children with hernia, hydrocele, and undescended testis. J. Pediatric Surg, 1999, 34: 552-555.

18. Shafey OA, Azzam ZA. Hernioplasty using the hernial sac in repair of inguinal hernia. Am. Surg, 1976, 42:268272.

19. Popov SD, Sorokina ZP. Aditional reinforcement of the zone of hernial opening from within use the hernia sac. Vestn. Khir, 1977, 118: 46-48.

20. Pucci JA. El uso del saco herniário autógeno como refuerzo en la plástica de hérnias inguinales. Ciência Médica, 1986, 1: 35-42.

21. Michowitz M, Schujman E, Solowiejczyk M. Aberrant adrenal tissue in the wall of a hernial sac. Am. Surg, 1979, p.67-69.

22. Chen KTK. Metastatic carcinoma in inguinal hernia sac. J. Surg. Oncology,1984, 25: 248-249.

Endereço para correspondência:

Cirênio de Almeida Barbosa

Rua Mica 31 apto 302 São Lucas

30240-330 - Belo Horizonte-MG

E-mail: cirenio@zipmail.com.br 